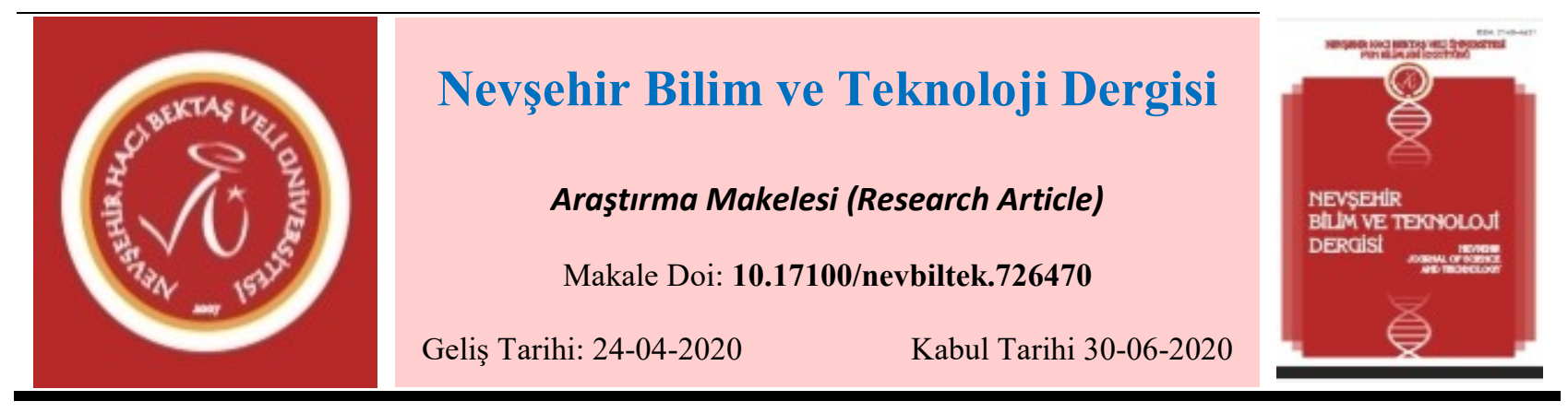

\title{
Sıcaklık Değişimi ve Dinamik Yol Yüklerinin Polipropilen Gıda Depolama Kutularının Deformasyonuna Etkisi
}

\author{
Meral Gülsen REİS ${ }^{1}$, Betül GÜLÇIMEN ÇAKAN ${ }^{2,}$, Ali DURMUŞ ${ }^{3}$, Murat REIS 4 \\ ${ }^{1}$ Bursa Uludă̆ Üniversitesi, Mühendislik Fakültesi, Makine Mühendisliği Bölümü, Bursa \\ ORCID ID: 0000-0003-0147-9108 \\ ${ }^{2}$ Bursa Uludağ Üniversitesi, Mühendislik Fakültesi, Makine Mühendisliği Bölümü, Bursa \\ ORCID ID: 0000-0003-1739-1143 \\ ${ }^{3}$ Bursa Uludağ Üniversitesi, Mühendislik Fakültesi, Makine Mühendisliği Bölümü, Bursa \\ ORCID ID: 0000-0003-2487-7344 \\ ${ }^{4}$ Bursa Uludă̆ Üniversitesi, Mühendislik Fakültesi, Makine Mühendisliği Bölümü, Bursa \\ ORCID ID: 0000-0001-5853-488X
}

Öz

Statik olarak istif halinde muhafaza edilebilen polipropilen gıda saklama kutuları taşıma esnasındaki iklim koşulları ve yoldan araca gelen dinamik yüklerin etkisiyle deformasyona uğrayarak ezilmesi problemi taşımacılıkta çok sık karșılașllan bir durumdur. Zira bir termoplastik türevi olan polipropilen de tıpkı diğer termo plastikler gibi sıcaklık değişimine karşı oldukça hassastır. Bununla beraber nakil edilen yükün gıda olması, polimer saklama kabının kırılma dayanımını artıran bir takım katkı maddelerinin kullanımını da sınırlandırmaktadır. Bunun sebebi ise pek çok katkı maddesi saklama kabının dayanımını artııı kırılganlığını azaltırken, diğer yandan insan sağlığını için risk oluşturan bileşenler içermektedir. Bu durumu bertaraf etmek için özel önlemlerin alınması ya da istif sayısının azaltılması gerekebilir bu da nakliye maliyetlerinin arttırılmasıyla sonuçlanır. Bu çalışmada polipropilen gıda saklama kutularının düzgün olmayan yol şartlarındaki mukavemet analizi deneysel ve bilgisayar simülasyonları (Abaqus yazılımı) yardımı ile yapılmakta ve belirtilen ivme ve yükleme koşulları için riskli sıcaklık değeri belirlenmektedir.

Anahtar Kelimeler: polipropilen, sıcaklık, dinamik yük, ezilme.

\section{The Effect of Temperature Change and Dynamic Road Loads on Deformation of Polypropylene Food Storage Boxes}

\begin{abstract}
Polypropylene food storage boxes, which can be stored in a statically stacked condition, are commonly exposed to deformation during transportation due to the climatic conditions and dynamic loads from the road. Polypropylene, which is a thermoplastic derivative, is very sensitive to temperature changes like other thermoplastics. Furthermore, the fact that the cargo being transported is food, the use of certain additives that increase the fracture strength of the polymer storage container is restricted. While many additives increase the strength of the storage container and make it less brittle, they also contain ingredients that pose a threat to human health. This requires particular measures to be taken in particular for the transport of foodstuffs or to limit the number of stacks, which means increased transport costs. In this study, strength analysis of polypropylene food storage boxes under uneven road conditions is carried out with the help of experimental and computer simulations (Abaqus software) and the risky temperature value is determined for the specified acceleration and loading conditions.
\end{abstract}

Keywords: polypropylene, temperature, dynamic load, crushing. 


\section{Giriş}

Polipropilen, kimyasal ve gıda ambalajlarından tekstil, kırtasiye, otomotiv parçaları, yeniden kullanılabilir kaplar ve laboratuar ekipmanlarına kadar çok sayıda uygulamada kullanılan bir termoplastik polimer türüdür $[1,2]$. Genel olarak termo-plastik malzemeler ve özellikle de polipropilen malzemelerin mekanik özellikleri sıcaklık değişiminden çok etkilenmektedir. Bunun yanında statik olarak taşıyabildikleri yükün çok daha az bir kısmı ile dahi ezilmeye maruz kalabilirler. Uygulamada en sık karşılaşılan problemlerden biri karayolu taşımacıllğında ortaya çıkmaktadır. Zira statik olarak birbiri üzerine konularak muhafaza edilebilen kutular, yol şartlarındaki düzgünsüzlükler ve sıcaklığın tesiri ile deformasyona maruz kalmakta ve tahrip olabilmektedir. Polipropilenin sıcaklığa bağlı mekanik özelliklerini belirleme ve iyileştirme çalışmaları oldukça yeni bir araştırma alanıdır. Bouvard ve dĭ̆. [3] deneysel olarak farklı gerilmeler, sıcaklıklar ve nominal zorlanma hızları altında iki yarı kristalize polimerin; polipropilen (PP) ve kopolimer polipropilen (ko-PP) mekanik davranışlarını incelemiştir. Grala ve diğ. [4], çekme testleriyle -20 ila 120 derecede ısıtılan polipropilenin viskoelastik davranışını gözlemlemişlerdir. Li ve diğ.[5], sıcaklı̆̆ın polipropilen polimerinin mekanik davranışı üzerindeki etkisini incelemiştir. Polimerin mekanik özelliklerini sırasıyla düşük sıcaklık ve yüksek sıcaklık için tek eksenli çekme testleriyle yapılmıştır. Sonuç olarak, hem akma gerilmesinin hem de malzemenin elastik modülünün sıcaklık artıkça azaldığını göstermişlerdir. Son yıllarda, birçok araştırmacı, termoplastiklerin mekanik özelliklerini çeşitli zorlanma oranlarında $[1,2,6,7]$ ve farklı sıcaklıklarda belirlemek için çalışmalar yapmıştır [5,8-11]. Polimerik malzemelerin sıcaklığa bağlı özellikleri bilinmesine ve statik - yarı statik davranışlarına rağmen, polimer malzemeler içerisinde kullanılan farklı katkı maddeleri ile sıcaklık ve dinamik yüklerin etkisini azaltmaya yönelik gelişmeler devam etmektedir. Ancak, bu katkı maddelerinin insan sağlığı üzerindeki etkisi de dikkate alınmalıdır.

Polipropilen kutular dinamik yol yüklerinin etkisi altında yüksek sıcaklıklardaki ezilme ve düşük sıcaklıklarda kırılma riski ile karşı karşıyadır. Bu durum göz önünde bulundurularak çalışmanın ilk bölümünde polipropilen malzemenin düşük ve yüksek sıcaklıklardaki mekanik özellikleri deneylerle tespit edilmektedir. Son bölümde ise elde edilen bu mekanik özellikler kullanılarak sonlu elemanlar yazılımı (Abaqus) yardımıyla mevcut tasarımın emniyetli çalışma şartları ve sıcaklık aralığı belirlenmektedir.

\section{Materyal ve Metot}

$\mathrm{Bu}$ çalışmada termoplastik bir malzeme olan polipropilenin sıcaklığa bağlı mekanik özelliklerindeki değişimi belirlemek üzere $-20^{\circ} \mathrm{C}, 20^{\circ} \mathrm{C}$ (oda sıcaklığı) ve $+60^{\circ} \mathrm{C}$ sıcaklık değerlerinde çekme testleri gerçekleştirilmiştir. Çekme testleri için U-Test marka Üniversal Test cihazı kullanılmıştır. Çekme testlerinden elde edilen malzeme modeli sonlu elemanlar yöntemiyle darbe analizi gerçekleştirmek için kullanılacağından çekme testleri maksimum hızda yani numuneler $500 \mathrm{~mm} / \mathrm{dk}$ çene hızıyla çekilmiştir. Her bir sıcaklık için ISO 527-23 standardına uygun olarak 3 adet numune test edilmiştir. Şekil 1'de ve Tablo 1'de çekme test numunelerine ait şematik ve geometrik boyutlar, Şekil 2'de ise üretilen numunelere yer verilmiştir. Test sonuçları düzenlenerek her bir sıcaklık için ortalama mühendislik gerilme-birim şekil değiştirme eğrileri oluşturulmuştur. Şekil 3'deki mühendislik eğrileri daha sonra gerçek gerilme-birim şekil değiştirme eğrilerine çevrilmiştir. Şekil 4'de gösterildiği gibi her bir sıcakllğa ait gerçek gerilme-birim şekil değiştirme eğrileri üzerinden elastisite modülü, akma gerilmesi ve plastik bölgeye ait gerilme-şekil değiştirme değerleri elde edilmiştir. Akma gerilmesinin belirlenmesinde offset yöntemi kullanılmıştır. Şekil 3'de görüleceği üzere artan sıcaklık elastisite modülü ve çekme dayanımını düşürürken, sünekliği arttırmıştır. Özellikle $-20^{\circ} \mathrm{C}$ 'deki kopmadaki şekil değişiminin diğer sıcaklıklara göre oldukça düşük olduğu görülmektedir. Bu değerler sonlu elemanlar analizlerinde kullanılmıştır. 


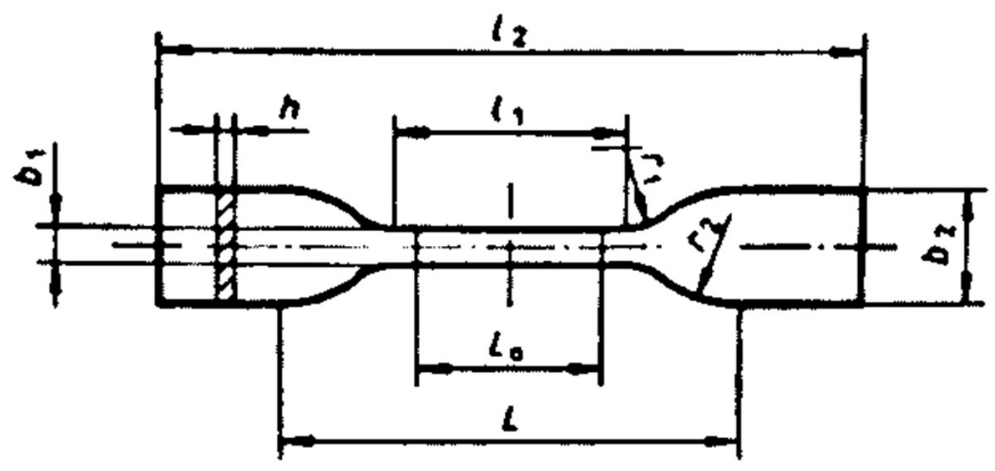

Şekil 1. 5A tipi çekme numunesi şematik [ISO 527-2: 1996]

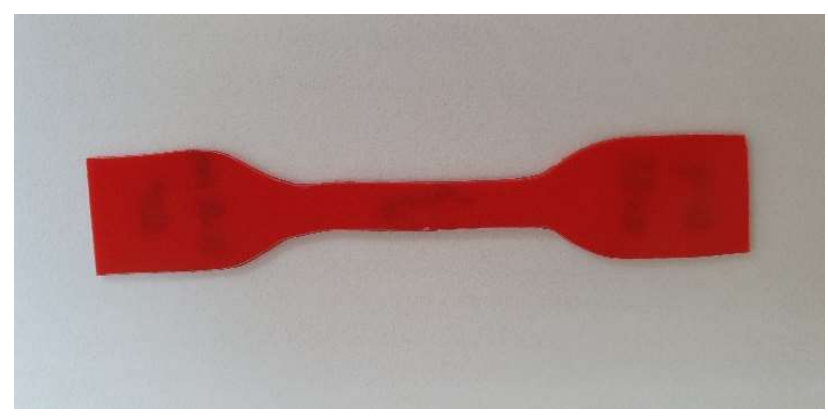

Şekil 2. Üretilen ISO 527-2 5A tipi çekme numuneleri

Tablo 1. ISO 527-2 5A tipi çekme numunesi ölçüleri [ISO 527-2: 1996]

\begin{tabular}{lll} 
Simge & Açıklama & Uzunluk (mm) \\
\hline $\mathrm{l}_{2}$ & Minimum toplam uzunluk & 75 \\
$\mathrm{~b}_{2}$ & Uçlarındaki genişlik & 12,5 \\
$\mathrm{l}_{1}$ & Dar paralel kenarların uzunluğu & 25 \\
$\mathrm{~b}_{1}$ & Dar paralel kenarların genişliği & 4 \\
$\mathrm{r}_{1}$ & Küçük yarı çap & 8 \\
$\mathrm{r}_{2}$ & Büyük yarı çap & 12,5 \\
1 & Kulplar arasındaki başlangıç mesafesi & 50 \\
$\mathrm{l}_{0}$ & Gösterge uzunluğu & 20
\end{tabular}

Catia programında oluşturulan dondurma kutularına ait CAD modelleri Abaqus sonlu elemanlar yazılımı içerisine alınarak sonlu elemanlar modeli oluşturulmuştur (Şekil 5). Oluşturulan dinamik analizler Abaqus Explicit çözümleyicisi ile koşturulmuştur.

İlk senaryoda kutular üst üste 8 sıra halinde taşınmaktadır. Bu durumda en alttaki kutu her biri 0,8 kg kütlesinde 7 adet kutuyu taşımaktadır ve toplam taşınan kütle 5,6 kg'dır. Bu yük $10 \mathrm{~mm}$ yüksekten en alttaki kutu üzerine serbest düşürülmektedir.

İkinci senaryoda kutular üst üste 15 sıra halinde taşınmaktadır. Bu durumda da en alttaki kutu her biri $0,8 \mathrm{~kg}$ kütlesinde 14 adet kutuyu taşımaktadır ve toplam taşınan kütle 11,2 kg'dır. Bu yük yine $10 \mathrm{~mm}$ yüksekten en alttaki kutu üzerine serbest düşürülmektedir.

Üstteki kutunun deformasyonu ihmal edildiği için rijit olarak kabul edilmiştir. Her bir senaryo için ilgili kütle üstteki rijit kutuya tanımlanmıştır. 
Alttaki şekil değiştirebilen kutu S4R (4 düğüm noktalı, azaltılmış integrasyon Shell yani kabuk eleman) eleman ile mesh atılmıştır. Üstteki kutu discrete rigid olarak tanımlandığı için bu kutuya da mesh atılmıştır. Tüm modeldeki toplam eleman ve nod sayısı sirasıyla 8973 ve 9151 'dir.

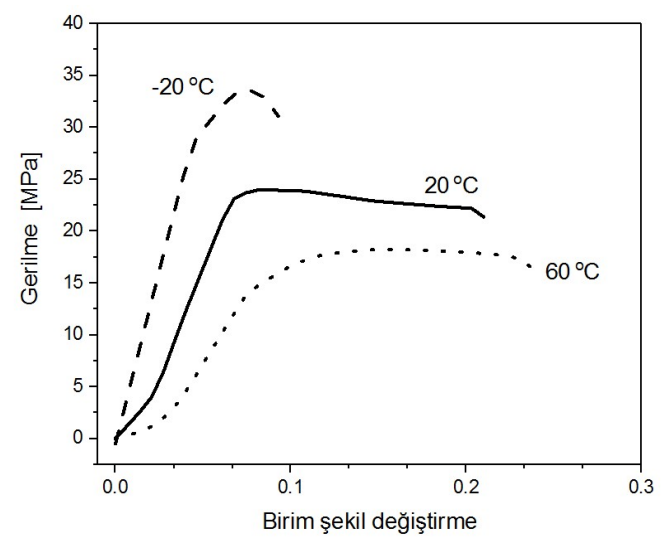

Şekil 3. Farklı sıcaklıklara ait ortalama mühendislik gerilme-birim şekil değiştirme eğrileri

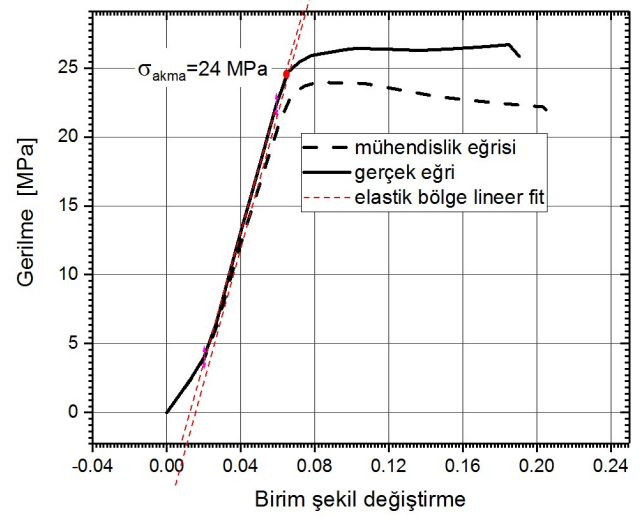

Şekil 4. $20^{\circ} \mathrm{C}$ ait mühendislik ve gerçek gerilme-birim şekil değiştirme eğrileri ve eğrinin analizi

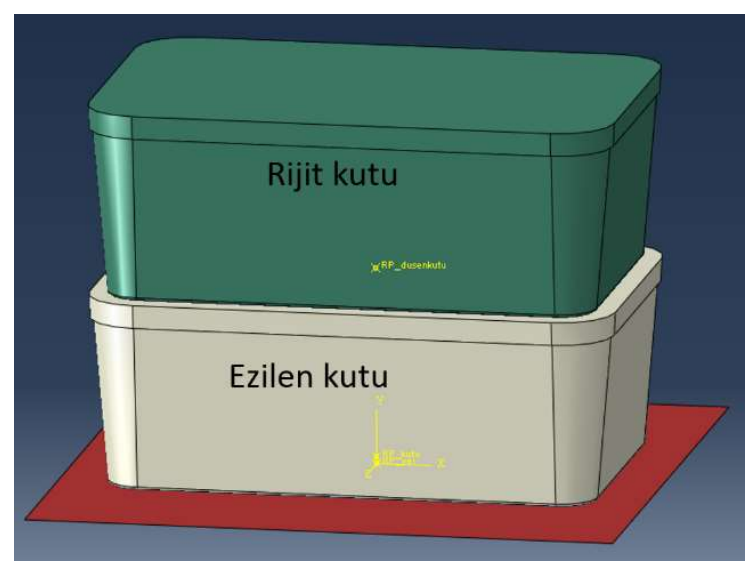

Şekil 5. Sonlu Elemanlar Modeli 


\section{Bulgular}

Her iki senaryo için Abaqus yazılımı kullanılarak yürütülen simülasyonlar sonucunda en altta kalan kutuya gelen ezilme kuvveti, sönümlenen enerji, ezilme miktarı, plastik şekil değiştirme ve Von-Mises mukayese gerilmesi eğrileri elde edilmektedir.

Şekil 6'da 8 sıra halinde taşınan kutular için, diğer 7 kutunun en altta kalan kutu üzerine 10 mm yüksekten tek bir cisim gibi düşme senaryosu halinde, en alttaki kutuya gelen ezilme kuvvetinin ezilme miktarı (deplasman) ile değişim eğrisi ve sönümlenen enerjinin zamana göre değişimi verilmektedir. Grafiklerden $-20^{\circ} \mathrm{C}$ ve $+20^{\circ} \mathrm{C}$ sıcaklıkta kuvvet deplasman eğrisinin oldukça benzer olduğu ancak $60^{\circ} \mathrm{C}$ 'de kuvvet eğrisinin hızlıca düştüğü görülmektedir. Sicaklık etkisi ile sünekleşen yapıda deformasyonlar hızla artmakta buna paralel olarak kuvvet deplasman eğrisi altında kalan alan artarak daha büyük bir çarpışma enerjisin sönümlenmesine sebep olmaktadır. Zira kutu diğer 7 kutunun yerçekimi potansiyel enerjisini sönümlemektedir ve dikey yer değiştirme ne kadar fazla olursa sönümlenen enerji de o seviyede büyük olacaktır.

Benzer şekilde Şekil 7'de 14 sıra halinde taşınan kutular (düşen kütle =11,2 kg) için en alttaki kutuya gelen ezilme kuvvetinin ezilme miktarı (deplasman) ve kutu tarafindan sönümlenen enerjinin zamanla değişim eğrileri verilmiştir. Sicaklığa bağlı olarak değerlerdeki değişim, kutuların 8 sıra halinde taşınması durumundakine benzer olduğu görülmektedir.

Şekil $8^{\prime}$ de $-20^{\circ} \mathrm{C} .+20^{\circ} \mathrm{C}$ ve $+60^{\circ} \mathrm{C}$ deki düşürme testi simülasyonları için plastik şekil değiştirme görselleri verilmiştir. Buradan $-20^{\circ} \mathrm{C}$ ve $+20^{\circ} \mathrm{C}$ sıcaklıklardaki kutuların çok ciddi bir plastik deformasyon yapmadan kutuları taşıyabildikleri ancak $+60^{\circ} \mathrm{C}$ deki kutunun ciddi bir plastik deformasyona maruz kaldığı görülmektedir.

Şekil 9'da $-20{ }^{\circ} \mathrm{C} .+20{ }^{\circ} \mathrm{C}$ ve $+60{ }^{\circ} \mathrm{C}$ deki düşürme testi simülasyonları için von-Mises mukayese gerilmesi görselleri verilmektedir. Buradan $-20^{\circ} \mathrm{C}$ ve $+20^{\circ} \mathrm{C}$ sıcaklıklardaki kutuların yükü taşımaya devam ettikleri bu nedenle yan yüzeylerde yüksek gerilmelerin oluştuğu ancak $+60^{\circ} \mathrm{C}$ deki kutunun bel verdiği bu nedenle burkularak katlanmış kesitin yükü artık taşıyamadığı anlaşılmaktadır.
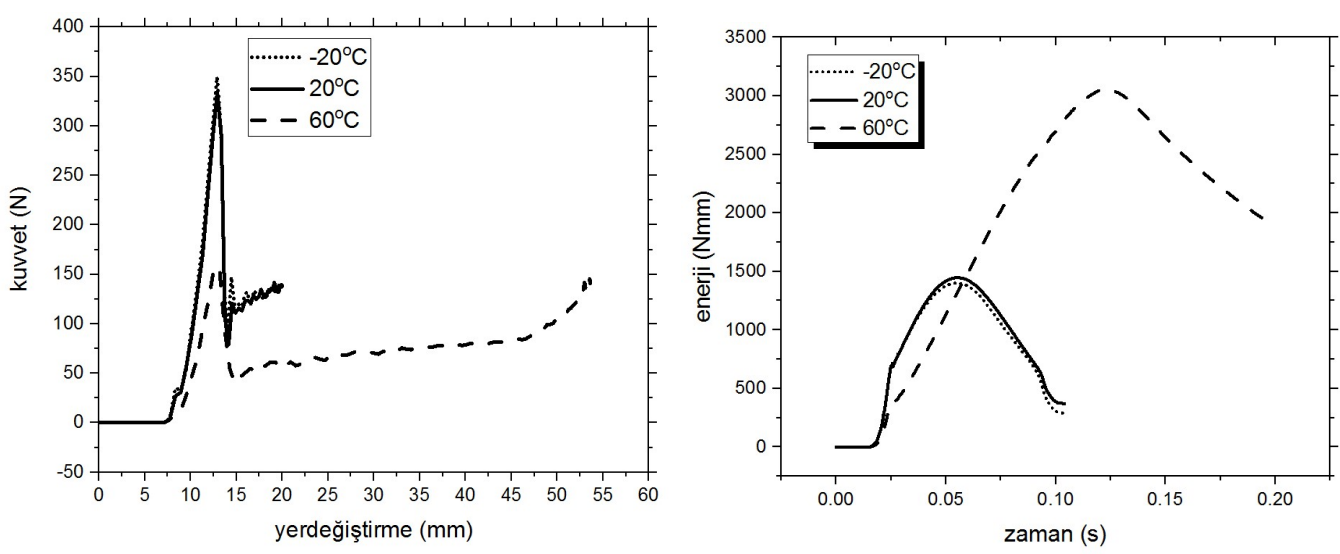

Şekil 6. 5,6 kg düşürme testi için ezilme kuvvetinin ezilme miktarı (yerdeğiştirme) ile değişimi 
Nevşehir Bilim ve Teknoloji Dergisi (2019), 9 (IMSTEC Özel Sayı),99-105
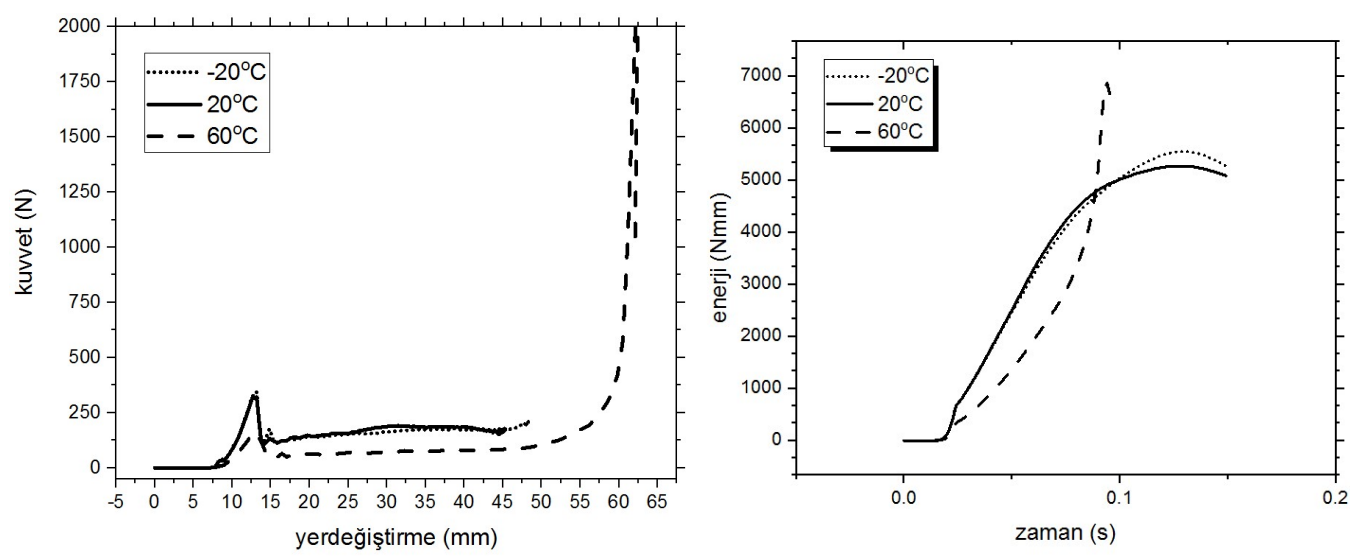

Şekil 7. 11,2 kg düşürme testi için ezilme kuvveti ve enerjinin zaman ile değişimi
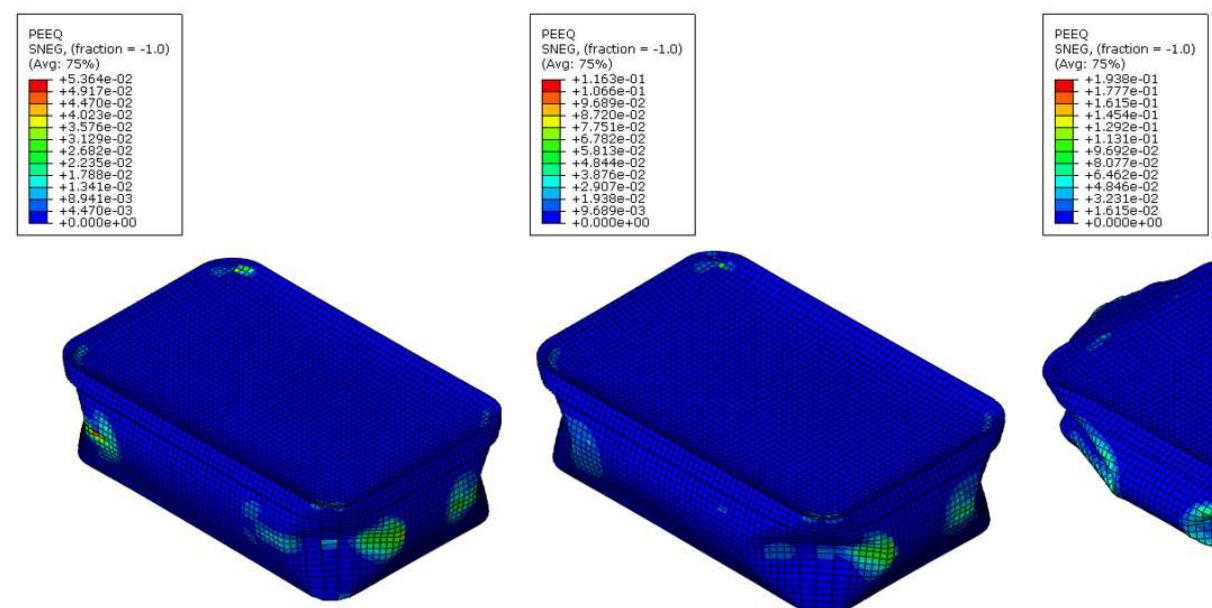

Şekil 8. $-20^{\circ} \mathrm{C} .+20^{\circ} \mathrm{C}$ ve $+60^{\circ} \mathrm{C}$ 'de kutuda gerçekleşen plastik şekil değiştirme dağılımı
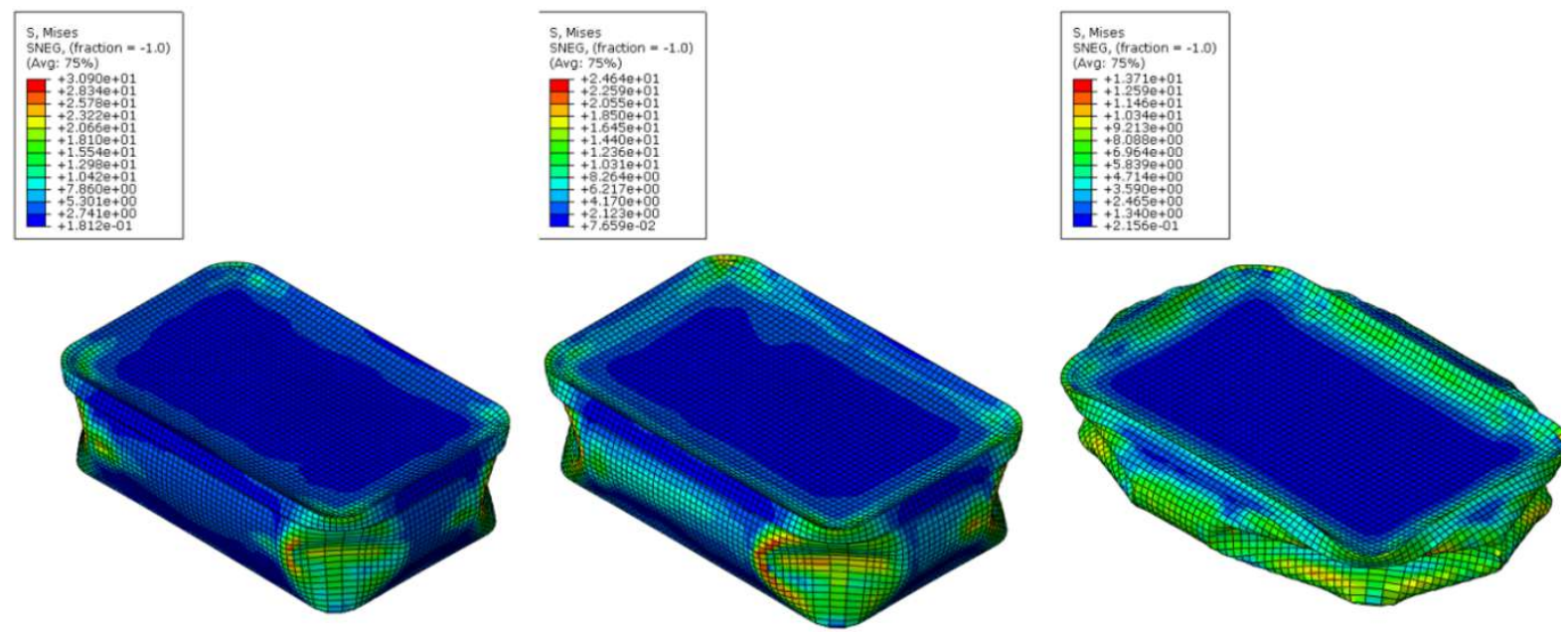

Şekil 9. $-20^{\circ} \mathrm{C} .+20^{\circ} \mathrm{C}$ ve $+60^{\circ} \mathrm{C}$ 'de kutuda gerçekleșen Von Mises gerilme dağılımı

\section{Tartışma ve Sonuç}

$\mathrm{Bu}$ çalışmada, yoğun kullanım alanına sahip bir termoplastik türü olan polipropilen malzemeden üretilmiş gıda saklama kutularının taşınması esnasında yol düzgünsüzlükleri sonucu ortaya çıkan dinamik yükler ve taşıma esnasında 
ortaya çıkan sıcaklık değişimleri etkisi altında oluşan deformasyon ve gerilmeler incelenmiştir. Nümerik sonuçlar statik olarak birbiri üzerine konularak istiflenen kutuların, yol şartlarındaki düzgünsüzlükler, ve sıcaklı̆̆ın tesiri ile ciddi deformasyona maruz kaldıklarını ve burkularak ezilebildiklerini göstermektedir. Özellikle sıcaklık $60^{\circ} \mathrm{C}$ 'ye çıkarıldığında deformasyonun ciddi oranda arttı̆̆g görülmüsşür. Ezilme riski söz konusu olduğunda model geometrisinde en kritik bölgeler köşelere yakın yan duvarların orta noktalarıdır. Gerilmelerin yüksek olduğu köşeleri yakın yan cidarlarda yapılacak kısmi kesit artımları ile kutunun hem ezilme, hem de darbe dayanımın artırılabilir.

\section{Kaynaklar}

[1] Richeton J., Ahzi S., Vecchio K.S., 'Influence of temperature and strain rate on the mechanical behavior of three amorphous polymers: characterization and modeling of the compressive yield stress'. Int. J. Solids Struct. 43, $2318-2335,2006$.

[2] Moy P., Gunnarsson C.A., Weerasooriya T., Chen W., 'Stress-Strain Response of PMMA as a Function of Strain-Rate and Temperature, Dynamic Behavior of Materials", Conference Proceedings of the Society for Experimental Mechanics, 1, 125-133, 2011.

[3] Bouvard J.L., Denton B., Freire L., Horstemeyer M.F., "Modeling the mechanical behavior and impact properties of polypropylene and copolymer polypropylene", Journal of Polymer Research, 23, 4, 2016.

[4] Grala M., Bartczak Z., Morphology R.A., 'Thermal and mechanical properties of polypropylene/SiO 2, nano composites obtained by reactive blending'. J. Polym. Res., 23, 1-19, 2016.

[5] Li G., Chen Y., Ruan B., 'A constitutive model of polymer at different temperature'. Aust. J. Mech. Eng., 52, 67-73, 2016.

[6] Zhou Y., Mallick P.K., 'Effects of temperature and strain rate on the tensile behavior of unfilled and talc-filled polypropylene Part II: constitutive equation.’’ Polym. Eng. Sci., 42, 2461-2470, 2002.

[7] Dar U.A., Zhang W., Xu Y., 'Thermal and strain rate sensitive compressive behavior of polycarbonate polymer - experimental and constitutive analysis'. J. Polym. Res., 21, 1-10, 2014.

[8] Mahieux C.A., Reifsnider K.L., 'Property modeling across transition temperatures in polymers: a robust stiffness-temperature model.'” Polymer 42, 3281-3291, 2001.

[9] Gibson A.G., Torres M.E.O., Browne T.N.A., "High temperature and fire behavior of continuous glass fiber / polypropylene laminates.” Compos A Appl. Sci. Manuf. 41,1219-1231, 2010.

[10] Sardon H., Irusta L., Santamaría P., 'Thermal and mechanical behaviour of self-curable water borne hybrid polyurethanes functionalized with (3-aminopropyl) triethoxysilane (APTES).” J. Polym. Res., 19, 1-9, 2012.

[11] Cao K., Wang Y., Wang Y., 'Experimental in vestigation and modeling of the tension behavior of polycarbonate with temperature effects from low to high strain rates.' Int.J.Solids Struct. 51:2539-2548, 2014. 